\title{
Effects of glucokinase activators GKA50 and LY2121260 on proliferation and apoptosis in pancreatic INS-1 beta cells
}

\author{
P. Wei • M. Shi • S. Barnum • H. Cho • T. Carlson • \\ J. D. Fraser
}

Received: 27 March 2009/Accepted: 11 June 2009/Published online: 30 July 2009

(C) Springer-Verlag 2009

\begin{abstract}
Aims/hypothesis Glucokinase (GK), an enzyme that phosphorylates glucose to form glucose 6-phosphate, serves as the glucose sensor that regulates insulin secretion in beta cells. GK activators (GKAs) activate GK via binding to an allosteric site of the enzyme. GKAs increase glucosestimulated insulin secretion and decrease blood glucose levels. Using the differentiated beta cell line INS-1, we investigated the role of GKAs in promoting beta cell growth and survival and preventing beta cell apoptosis induced by chronic exposure to high levels of glucose.

Methods Proliferation was assessed using BrdU incorporation. Apoptosis was measured using caspase-3 activity. Immunoblot analysis was used to detect protein levels and the degree of phosphorylation.

Results The GK agonists GKA50 and LY2121260 increased both cell replication and cell numbers when tested at basal levels of glucose $(3 \mathrm{mmol} / \mathrm{l})$ in INS-1 cells. GKAs promoted INS-1 cell proliferation via upregulation of insulin receptor substrate-2 and subsequent activation of protein kinase B phosphorylation. GKA50 also prevented the INS-1 cell apoptosis that was induced by chronic high glucose conditions, probably via an increase in GK protein levels and normalisation of the apoptotic protein BCL2-associated agonist of cell death (BAD) and its phosphorylation. As a result of the reduction in cell apoptosis, GKA50 prevented cell loss and maintained glucose-stimulated insulin secretion.
\end{abstract}

\footnotetext{
P. Wei $(\bowtie) \cdot$ M. Shi $\cdot$ S. Barnum $\cdot$ H. Cho $\cdot$ T. Carlson

J. D. Fraser $(\square)$

Diabetes Biology Department, Pfizer Global Research

and Development, La Jolla Laboratories,

10724 Science Center Drive,

La Jolla, CA 92121, USA

e-mail: ping.wei@pfizer.com

e-mail: jim.fraser@pfizer.com
}

In addition, the anti-apoptotic activity of GKA50 was significantly abrogated by other GKAs that do not inhibit apoptosis, suggesting that direct binding of GKA50 to GK is essential for its anti-apoptotic effect.

Conclusion/interpretation Our results suggest novel roles of GKAs in promoting beta cell growth and preventing chronic-hyperglycaemia-induced beta cell apoptosis. Thus, GKAs may provide novel therapeutics that increase beta cell mass to maintain euglycaemia in diabetes.

Keywords Apoptosis - Beta cell - Glucokinase activator · Proliferation

$\begin{array}{ll}\begin{array}{l}\text { Abbreviations } \\ \text { (p)BAD }\end{array} & \begin{array}{l}\text { (phosphorylated) BCL2-associated } \\ \text { agonist of cell death }\end{array} \\ \text { BAX } & \begin{array}{l}\text { BCL2-associated X protein } \\ \text { Half effective concentration }\end{array} \\ \text { EC }_{50} & \begin{array}{l}\text { Glyceraldehyde-3-phosphate } \\ \text { dehydrogenase }\end{array} \\ \text { GK } & \text { Glucokinase } \\ \text { GKA } & \text { Glucokinase activator } \\ \text { GLP-1 } & \text { Glucagon-like peptide-1 } \\ \text { IRS-2 } & \begin{array}{l}\text { Insulin receptor substrate-2 } \\ \text { (phosphorylated) Protein kinase B }\end{array} \\ \text { (p)PKB/AKT } & \text { Voltage-dependent anion channel }\end{array}$

\section{Introduction}

Chronic exposure to hyperglycaemia leads to a progressive loss of beta cell mass by inducing beta cell death without a sufficient compensatory increase in the rate of beta cell production. In type 2 diabetes, the onset of the disease is not only caused by dysfunction of insulin secretion but also 
significant loss of beta cell mass that no longer compensates for insulin resistance [1,2]. Therefore, therapeutics that promote survival and prevent apoptosis in beta cells are highly desirable as they may preserve beta cell function and delay or prevent the onset of diabetes.

Glucokinase (GK), a member of the hexokinase family, catalyses the initial step in glycolysis. The enzyme phosphorylates glucose to glucose 6-phosphate and acts as a sensor for glucose-stimulated insulin secretion in beta cells [3]. Inactivating mutations in GK have been associated with maturity-onset diabetes of the young, which is characterised by early-onset and persistent hyperglycaemia $[4,5]$. Conversely, activating mutants increase insulin secretion to a level that induces hypoglycaemia in some cases [4]. Recently, small molecules that bind to an allosteric site of GK and increase its activity have been discovered. These GK activators (GKAs) enhance hepatic glucose disposal in mice and stimulate glucose-stimulated insulin secretion in isolated pancreatic islets, hence providing potentially novel treatments for diabetes [6].

In addition to functioning as a glucose sensor and modulator of insulin secretion in beta cells, GK has recently been reported to play potentially important roles in the regulation of beta cell growth and survival. Terauchi et al. showed that beta cell specific $G k^{+/-}$mice failed to display compensatory beta cell replication in response to insulin resistance induced by a high-fat diet, suggesting a critical role of GK in beta cell hyperplasia and protection against diabetes [7]. Furthermore, GK has also been reported to be potentially involved in preventing beta cell apoptosis [8]. Danial et al. revealed that GK resides in a mitochondrial complex with BCL2-associated agonist of cell death (BAD), a pro-apoptotic protein that acts as an apoptotic sentinel, responding to abnormalities in glucose metabolism [9]. Subsequently, Kim et al. demonstrated that chronic exposure to elevated glucose causes a reduction in GK production, BAD phosphorylation and interaction of GK with mitochondrial voltage-dependent anion channels (VDACs) [10]. Decreased binding of GK to the mitochondria allows apoptotic BCL2-associated X protein (BAX) to bind to VDAC and ultimately leads to an increase in beta cell apoptosis. Taken together, the evidence suggests that GK may be integral for the interplay between glucose metabolism and cell growth and apoptosis in pancreatic beta cells.

The goal of this study was to determine whether an increase in GK activity by GKAs could promote beta cell growth and prevent apoptosis induced by chronic exposure to high glucose levels. We discovered that under basal glucose conditions, the GK activators GKA50 and LY2121260 increase both INS-1 beta cell replication and cell numbers via upregulation of insulin receptor substrate-2 (IRS-2) and activation of protein kinase B (PKB/AKT). We also found that GKA50 specifically increases the level of GK protein and normalises that of apoptotic protein $\mathrm{BAD} /$ phosphorylated BAD (pBAD) under conditions of chronic high glucose, thereby significantly reducing INS-1 cell apoptosis caused by such conditions. Our results indicate that GK activity plays an important role in beta cell survival and apoptosis. They also suggest that in addition to stimulation of insulin secretion and normalisation of glucose, GKAs may result in beta cell preservation and an increase in beta cell mass by promoting growth and preventing apoptosis of beta cells.

\section{Methods}

Compounds All compounds were synthesised at Pfizer, La Jolla, CA, USA.

Cell culture INS-1 cells were cultured in growth medium composed of RPMI 1640 medium (Invitrogen, Carlsbad, CA, USA), containing $11 \mathrm{mmol} / \mathrm{l}$ glucose, $10 \%$ (vol./vol.) fetal bovine serum (Hyclone, Logan, UT, USA), $50 \mu \mathrm{mol} / 1$ 2-mercaptoethanol, $1 \mathrm{mmol} / \mathrm{l} \mathrm{Na-pyruvate,} 2 \mathrm{mmol} / \mathrm{l}$ glutamine, $100 \mathrm{U} / \mathrm{ml}$ penicillin and $100 \mu \mathrm{g} / \mathrm{ml}$ streptomycin. Cells were maintained at $37^{\circ} \mathrm{C}$ in a humidified incubator gassed with $5 \% \mathrm{CO}_{2}$.

GK-coupled enzyme assay Production and purification of GK recombinant proteins has been described previously [11].

The half effective concentration $\left(\mathrm{EC}_{50}\right)$ and $V_{\max }$ values of the GKAs were determined using a pyruvate kinase/ lactate dehydrogenase-coupled assay. Briefly, the assay was performed in the presence of serial dilutions of test compounds, $5 \mathrm{mmol} / \mathrm{l}$ glucose and $1 \mathrm{mmol} / 1$ ATP at $25^{\circ} \mathrm{C}$. The final assay buffer also contained $50 \mathrm{mmol} / 1$ HEPES, $\mathrm{pH} 8.0,2 \mathrm{mmol} / 1 \mathrm{MgCl}_{2}, 25 \mathrm{mmol} / \mathrm{l} \mathrm{KCl}, 0.7 \mathrm{mmol} / 1 \mathrm{NADH}$, $2 \mathrm{mmol} / \mathrm{l}$ dithiothreitol, $0.2 \mathrm{mmol} / 1 \mathrm{phosphoenolpyruvate,}$ $0.1 \%$ BSA and 1 unit $/ \mathrm{ml}$ of pyruvate kinase/lactate dehydrogenase. Reactions were initiated by the addition of GK and monitored by the depletion of NADH at $340 \mathrm{~nm}$.

$\mathrm{EC}_{50}$ and \% activation were calculated by the following equations:

$y=$ minimal reading $+($ maximal - minimal $) /\left[1+10^{\left(\log ^{10} \mathrm{EC}^{50}-x\right)}\right]$ $\%$ maximum activation $=\left(V_{\mathrm{a}} / V_{0}-1\right) \times 100$

where $x$ is the logarithm $m_{10}$ of the compound concentration, $y$ is $V_{\mathrm{a}} / V_{0}, V_{\mathrm{a}}$ is activity in the presence of activator and $V_{0}$ is activity in the absence of activator. 
Proliferation assay INS-1 cells were plated in 96 well plates at $1.5 \times 10^{5}$ cells/well in growth medium. Next day, the cells were washed once with PBS and incubated overnight in starvation medium in which serum was replaced with $0.1 \%$ BSA based on the method of Wang et al. [12]. The starvation medium also lacked glucose and sodium pyruvate. For BrdU incorporation, cells were subsequently stimulated for $24 \mathrm{~h}$ in starvation medium supplemented with $3 \mathrm{mmol} / \mathrm{l}$ glucose and differing concentrations of compounds. BrdU solution was then added and cells were incubated for additional $6 \mathrm{~h}$. BrdU incorporation was detected using ELISA following the manufacturer's instructions (Roche Diagnostics, Indianapolis, IN, USA). To obtain cell numbers, cells were stimulated for $48 \mathrm{~h}$, then trypsinised and counted in the presence of Trypan blue using a haemocytometer.

Apoptosis assay INS-1 cells were plated in 96 well plates at $5 \times 10^{4}$ cells/well. Unless otherwise stated, cells were treated for 3 days in growth media with different amounts of glucose in the absence or presence of different concentrations of compounds. Apoptosis was evaluated using the Caspase-Glo 3/7 Assay kit according to the manufacturer's instructions (Promega, Madison, WI, USA).

Insulin secretion assay Glucose-stimulated insulin secretion by GKAs was measured using untreated cells. Briefly, INS-1 cells were plated in 96 well plates at $7.5 \times 10^{4}$ cells/ well. Next day, they were cultured overnight in starvation medium containing $2.5 \mathrm{mmol} / 1$ glucose. After starvation, the cells were washed once with KRB and then incubated in $\mathrm{KRB}$ for $30 \mathrm{~min}$. Insulin secretion was performed in KRB containing $6 \mathrm{mmol} / \mathrm{l}$ of glucose and different concentrations of test compounds for $3 \mathrm{~h}$.

Stimulation of insulin secretion in the cells pretreated with high glucose and compounds was conducted as described below. INS-1 cells were plated in 96 well plates at $5 \times 10^{4}$ cells/well. Next day, cells were treated with high glucose (40 mmol/l) and/or compounds at indicated concentrations for 3 days. The medium was then removed and replaced with starvation medium containing $2.5 \mathrm{mmol} / 1$ glucose. After $2 \mathrm{~h}$ incubation, cells were washed once with KRB and incubated with KRB for additional $30 \mathrm{~min}$. Insulin secretion was performed in KRB supplemented with $16 \mathrm{mmol} / 1$ of glucose for $2 \mathrm{~h}$. For measurement of insulin, samples were diluted and assayed by ELISA according to the manufacturer's instructions (ALPCO, Salem, NH, USA).

Western blot analysis Following treatments, INS-1 cells were lysed in CelLytic cell lysis reagent (Sigma, St Louis, MO, USA). The lysates were collected after centrifugation at $13,000 \mathrm{rpm}$ for $10 \mathrm{~min}$ at $4^{\circ} \mathrm{C}$. Protein concentration was measured using the Bio-Rad protein assay kit (Bio-Rad,
Hercules, CA, USA). Protein samples were resolved by electrophoresis on SDS-polyacrylamide gel (Invitrogen). Following transfer to nitrocellulose membrane, the membrane was subjected to immunoblot analysis using antibodies against IRS-2, GK (Santa Cruz Biotech, Santa Cruz, CA, USA), PKB/AKT, phosphorylated PKB/AKT (pPKB/AKT), BAD, pBAD (Cell Signaling Technology, Danvers, MA, USA), and glyceraldehyde-3-phosphate dehydrogenase (GAPDH; EMD Chemicals, San Diego, CA, USA). Secondary antibodies (Alexa Fluor 680 antibodies) were purchased from Invitrogen and IRDye800 Conjugates from Rockland Immunochemicals (Gilbertsville, PA, USA). The images were analysed using an Odyssey Infrared Imaging System from LICOR Biosciences (Lincoln, NE, USA).

\section{Results}

GKA50 and LY2121260 stimulate proliferation of INS-1 cells through upregulation of IRS-2 To investigate the effect of GKAs on beta cell proliferation and apoptosis, we selected GK activator compounds with different structure scaffolds as reported in the literature, such as AstraZeneca's GKA1 and GKA50, Lilly's LY2121260 and Banyu's Compound A [13-16] (Fig. 1a). These compounds activated human GK enzymatic activity with various potencies $\left(\mathrm{EC}_{50}\right)$ and different maximal enzyme activities $\left(V_{\max }\right)$, and also stimulated insulin secretion in the pancreatic insulinoma cell line, INS-1 (Fig. 1b).

Stimulation of beta cell proliferation was performed using either a stimulatory concentration of glucose $(15 \mathrm{mmol} / \mathrm{l})$ or a test compound (GKA50 or LY2121260) at basal glucose concentration ( $3 \mathrm{mmol} / \mathrm{l})$. INS-1 cell proliferation was measured by BrdU incorporation, which reflects the rate of DNA synthesis. BrdU incorporation in the presence of $3 \mathrm{mmol} / \mathrm{l}$ glucose served as control and was set as $100 \%$. Under basal glucose conditions, GKA50 and LY2121260 stimulated cell proliferation five- to sevenfold. The stimulation was dose-dependent, with $\mathrm{EC}_{50}$ values ranging from 1 to $2 \mu \mathrm{mol} / 1$ (Fig. 2a). At $48 \mathrm{~h}$ post stimulation with $15 \mathrm{mmol} / 1$ glucose or $5 \mu \mathrm{mol} / 1$ compound, cell numbers were also increased as a result of enhancement of cell proliferation (Fig. 2b).

It has been reported that $15 \mathrm{mmol} / \mathrm{l}$ glucose promotes INS-1 proliferation, most likely via upregulation of the IRS-2 and PKB/AKT pathways [17]. We examined whether GKAs were able to stimulate IRS-2 production at the basal glucose concentration using western blot analysis. While treatment with $5 \mu \mathrm{mol} / 1$ GKA50 for $8 \mathrm{~h}$ caused a small but reproducible increase in IRS-2 protein levels, the effect of LY2121260 was comparable with that of $15 \mathrm{mmol} / \mathrm{l}$ glucose (Fig. 2c). IRS-2 elevation also paralleled activation of PKB/ 
a<smiles>C=C(C)C1CCC(C(=C)C2CC(CC(C)C)CC(CC(C)CC3CCCCC3)C2)CC1</smiles>

GKA50

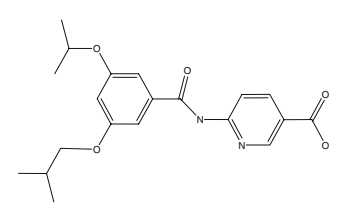

GKA1

b

\begin{tabular}{cccccc}
\hline \multirow{2}{*}{ Compound } & \multicolumn{2}{c}{ Biochemical } & & \multicolumn{2}{c}{ Cellular } \\
\cline { 2 - 3 } \cline { 5 - 6 } & $\begin{array}{c}\mathrm{EC}_{50} \\
(\mu \mathrm{mol} / 1)\end{array}$ & $\begin{array}{c}V_{\max } \\
(\%)\end{array}$ & & $\begin{array}{c}\mathrm{EC}_{50} \\
(\mu \mathrm{mol} / 1)\end{array}$ & $\begin{array}{c}\text { Max } \\
\text { act. }(\%)\end{array}$ \\
\hline GKA50 & 0.022 & 74 & & 0.065 & 75 \\
Compound A & 0.127 & 212 & & 0.221 & 136 \\
LY2121260 & 0.420 & 305 & & 0.074 & 130 \\
GKA1 & 1.130 & 147 & & $>1$ & 142 \\
\hline
\end{tabular}

Fig. 1 a Chemical structures and $\mathbf{b}$ biochemical and cellular activities of selected glucokinase activators. Biochemical and cellular assay conditions are described in the "Methods" section (GK-coupled enzyme assay and insulin-secretion assay, respectively). The values in b represent the means of at least two independent experiments. Max. act., maximum activity

AKT via phosphorylation with no change in the production of this protein. The results suggest that GKAs stimulate INS-1 cell proliferation at least in part via specific increase of IRS-2 signalling and PKB/AKT activation in the cells.

GKA50, but not GKAs with different structural scaffolds, reduces INS-1 cell apoptosis induced by chronic high glucose It has been observed that conditions of chronic high glucose induce beta cell apoptosis, possibly through downregulation of GK protein levels [10]. Thus, we sought to investigate whether enhancement of GK activity by GKAs would protect beta cells against apoptosis induced by high glucose. We first treated INS-1 cells with different concentrations of glucose for 3 days. Compared with normal culture conditions (11 $\mathrm{mmol} / \mathrm{l}$ glucose), treatment of INS-1 cells with $20 \mathrm{mmol} / \mathrm{l}$ and higher glucose concentrations caused a marked increase in apoptosis, as measured with caspase-3 activities (Fig. 3a). The effect of high glucose on apoptosis induction was time dependent as the apoptotic signals increased over the course of treatment (Fig. 3b). We next investigated the effect of GKAs on prevention of beta cell apoptosis. INS-1 cells were simultaneously treated with $40 \mathrm{mmol} / \mathrm{l}$ glucose and $1.2 \mu \mathrm{mol} / \mathrm{l} \mathrm{GKA} 50$ for $2-4$ days. The caspase- 3 activity in the presence of $40 \mathrm{mmol} / \mathrm{l}$ glucose was set as $100 \%$. After 2 days from commencement of treatment, cells treated with GKA50 had a $20 \%$ reduction in high-glucose-induced apoptosis, with a maximal reduction of $30-40 \%$ by days 3 and 4 (Fig. 3c). No further reduction was observed at later time points (data not shown). Our results are consistent with previous data indicating that overproduction of GK in MIN6N8 cells caused a partial reduction of apoptosis [10].

To investigate if other GKAs have a similar anti-apoptotic effect, we tested several GKAs including GKA1, LY2121260, and Compound A. However, we discovered that only GKA50 and GKA1, which were derived from the same chemical series, were able to ameliorate apoptosis (Fig. 3d). The other two compounds did not display any anti-apoptotic activity. GKA1 is $\sim 50$-fold less potent in its enzymatic activity than GKA50 (Fig. 1), which might explain its marginal anti-apoptotic effect in our assays.
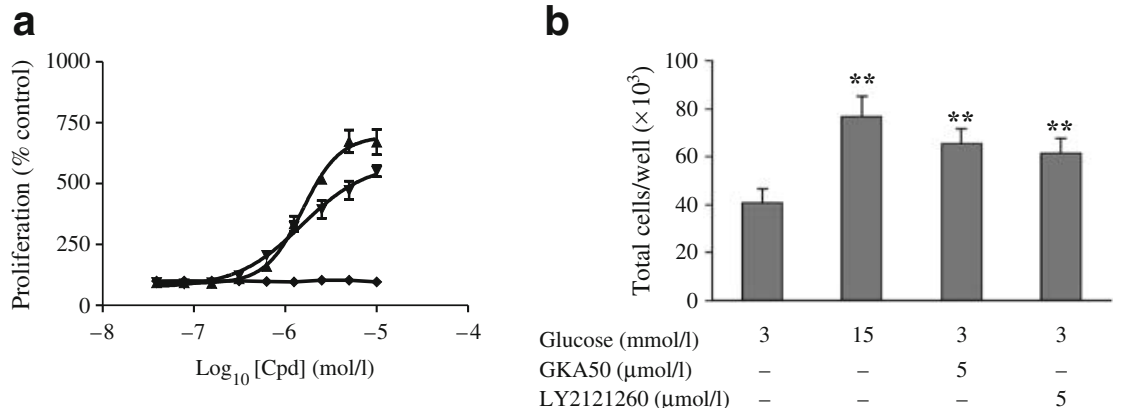

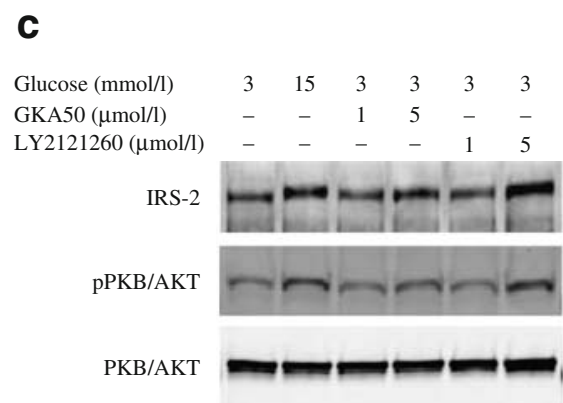

Fig. 2 GK activators enhance INS-1 cell proliferation through upregulation of IRS-2 and activation of PKB/AKT. INS-1 cells were starved overnight with $3 \mathrm{mmol} / 1$ glucose. a INS-1 cells were stimulated with different concentrations of GKA50 or LY2121260 for $24 \mathrm{~h}$. Cell proliferation was measured by BrdU incorporation. Triangle, LY2121260; inverted triangle, GKA50; diamond, DMSO. b INS-1 cells were stimulated with either $15 \mathrm{mmol} / 1$ glucose or
$5 \mu \mathrm{mol} / 1$ GKA50 and LY2121260 for $48 \mathrm{~h}$. Cells were then trypsinised and counted. c INS-1 cells were stimulated with either $15 \mathrm{mmol} / \mathrm{l}$ glucose or $5 \mu \mathrm{mol} / \mathrm{l}$ GKA50 and LY2121260 for $8 \mathrm{~h}$. Cell lysates were subjected to immunoblot analysis for total IRS-2, pPKB/ $\mathrm{AKT}$ and $\mathrm{PKB} / \mathrm{AKT}$. The results shown represent the mean $\pm \mathrm{SEM}$ from triplicate experiments. ${ }^{* *} p<0.01$ 
a

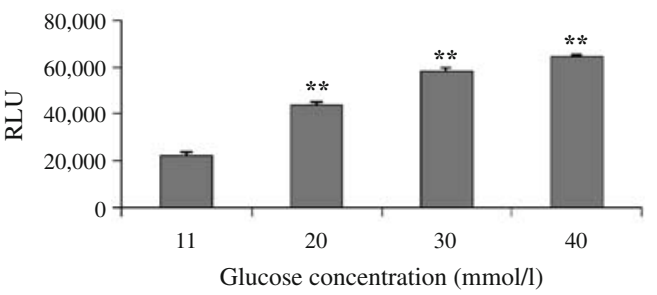

C

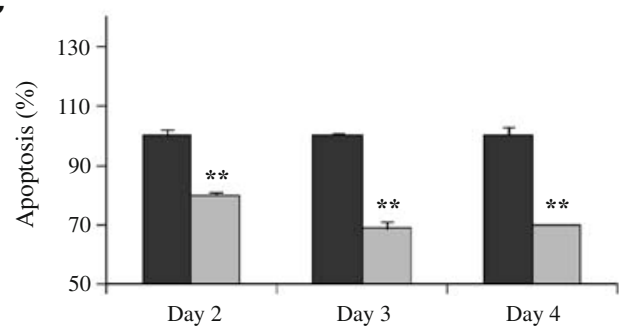

b

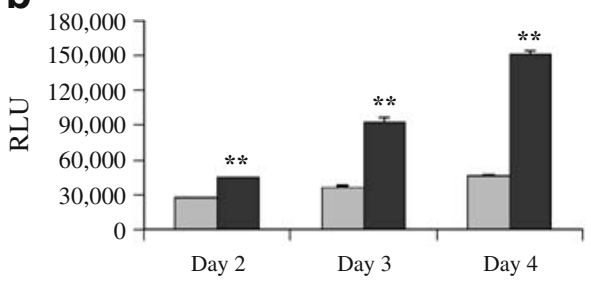

d

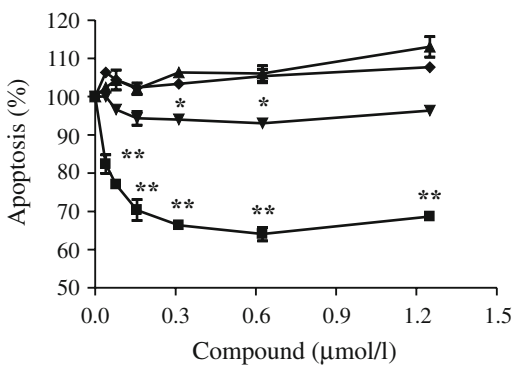

Fig. 3 GKA50 treatment reduces apoptosis induced by chronic high glucose. INS-1 cells were treated with a increasing concentrations of glucose for 3 days or b $40 \mathrm{mmol} / 1$ glucose for 2-4 days and relative luciferase units (RLU) were then determined. Light grey bar, $11 \mathrm{mmol} / 1$ glucose; dark grey bar, $40 \mathrm{mmol} / 1$ glucose. c INS-1 cells were treated with $40 \mathrm{mmol} / \mathrm{l}$ glucose alone or combined with $1.2 \mu \mathrm{mol} / 1$ GKA50 for $2-4$ days. Light grey bar, $1.2 \mu \mathrm{mol} / 1$ GKA50;

GKA50 prevents INS-1 cell loss induced by chronic high glucose and maintains insulin secretion in INS-1 cells Because it inhibits apoptosis, GKA50 was expected to prevent the beta cell loss provoked by high levels of glucose. To confirm this hypothesis, the total number of INS-1 cells treated with $40 \mathrm{mmol} / 1$ glucose in the presence or absence of $1.2 \mu \mathrm{mol} / \mathrm{l}$ of GKA50 was assessed daily for up to 3 days. We found that as chronic high glucose exposure caused apoptosis, it resulted in a reduced number of cells compared with normal glucose controls. The reduction in cell number by high glucose was evident after 1 day of treatment (Fig. 4a) and was statistically significant on day 3 (Fig. 4c). Treatment with GKA50 completely blocked the cell loss but treatment with LY2121260 had no activity (Fig. 4c).

To examine if GKA50 preserves insulin secretion, two sets of cells were treated with $40 \mathrm{mmol} / \mathrm{l}$ glucose and different amounts of GKA50 for 3 days. One set of the cells were measured for caspase- 3 activity. The medium containing high glucose and test compound was removed from the other set of cells, and was replaced with medium containing $2.5 \mathrm{mmol} / 1$ glucose. After $2 \mathrm{~h}$ recovery, the cells were stimulated for insulin secretion with $16 \mathrm{mmol} / 1$ glucose as described in the Methods. While GKA50 pre-treatment decreased cell apoptosis, insulin secretion was maintained. Inhibition of cell apoptosis and preservation of glucosestimulated insulin secretion were tightly correlated and dark grey bar, no compound. d INS-1 cells were treated with $40 \mathrm{mmol} / \mathrm{l}$ glucose and increasing concentrations of compound for 3 days. Caspase-3 activity was measured. Triangle, LY2121260; diamond, Compound A; inverted triangle, GKA1; square, GKA50. The results shown represent the mean \pm SEM from one of three independent experiments performed in triplicate. ${ }^{*} p<0.05,{ }^{*} p<0.01$

dependent on the concentration of GKA50. As GKA50 concentration increased, there was less apoptosis and more glucose-stimulated insulin secretion (Fig. 4d).

GKA50 reduces chronic-high-glucose-induced apoptosis via modulation of $G K$ and apoptotic protein BAD To investigate the potential mechanism by which GKA50 exerts its anti-apoptotic effect, we performed western blot analysis and examined how GKA50 regulates target proteins. As shown in Fig. 5, exposure of INS-1 cells to chronic high glucose did not seem to change GK levels, contrary to the effect in MIN6N8 cells [10]. Chronic high glucose exposure caused a moderate reduction of BAD and pBAD in INS- 1 cells ( $30 \%$ reduction). One explanation for the observed discrepancies could be the different cell lines under study (rat INS-1 vs mouse MIN6N8). Despite the rather modest changes seen with chronic high glucose, we observed increased GK production ( $\sim 1.7$-fold) and coordinate normalisation of $\mathrm{BAD}$ and phosphorylated $\mathrm{BAD}$ (pBAD) at $1.2 \mu \mathrm{mol} / 1 \mathrm{GKA} 50$, the concentration where maximal inhibition of apoptosis by this compound was observed (Fig. 3d). The specific regulation of GK and $\mathrm{BAD} / \mathrm{pBAD}$ was confirmed by the finding that LY2121260 was not able to elicit changes similar to those achieved with GKA50. This is consistent with LY2121260 not preventing apoptosis (Fig. 3d). These results suggest that induction of GK and normalisation of $\mathrm{BAD} / \mathrm{pBAD}$ with concomitant 

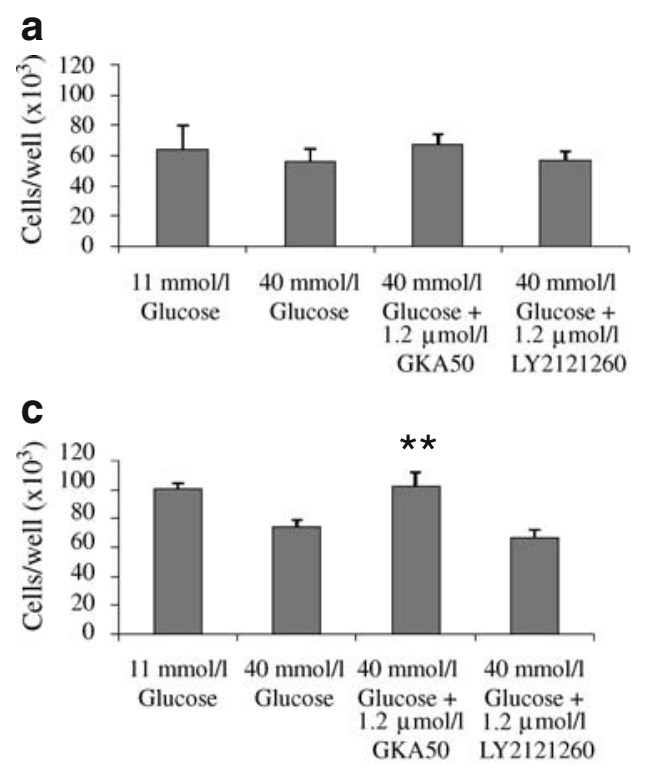

Fig. 4 GKA50 prevents reduction of cell number by chronic high glucose and preserves the insulin secretory function of INS-1 cells. INS-1 cells were treated with either $11 \mathrm{mmol} / \mathrm{l}$ glucose or $40 \mathrm{mmol} / \mathrm{l}$ glucose (in the absence or presence of compound) for 3 days. a-c Cells were trypsinised and counted on day 1 (a), day 2 (b) and day 3 (c). The results shown represent the mean + SEM from quadruplicate assays. ${ }^{* *} p<0.01,40 \mathrm{mmol} / 1$ glucose vs $40 \mathrm{mmol} / 1$ glucose plus $1.2 \mu \mathrm{mol} / 1$ GKA50. d Two sets of cells were treated under identical

amelioration of apoptosis may occur through a mechanism unique to GKA50.

Production of BAX in INS-1 cells was induced by chronic high glucose levels, and the induction was not affected by the addition of GKAs (Fig. 5). An increase in BAX resulting from exposure to high glucose levels was also observed in MIN6N8 cells [10]. Although overproduction of GK in stably transfected MIN6N8 cells completely blocked BAX induction by high glucose, the elevation of BAX seen in INS-1 was not altered by GKA50, despite the fact that GK protein was increased by incubation with test compound. It is possible that this discrepancy was caused by the difference between constant high GK levels in stably transfected cells vs transient induction of GK by the compound.

The anti-apoptotic effect of GKA50 is decreased by other GK activators that do not inhibit apoptosis induced by chronic high glucose To address whether the anti-apoptotic effect of GKA50 is due to its direct binding to GK, competition experiments were performed in the presence of GKA50 and other GKAs lacking anti-apoptotic activity, such as LY2121260 and Compound A. These GKAs were designed to bind to the same allosteric site of GK and have shown no effect on the inhibition of apoptosis induced by
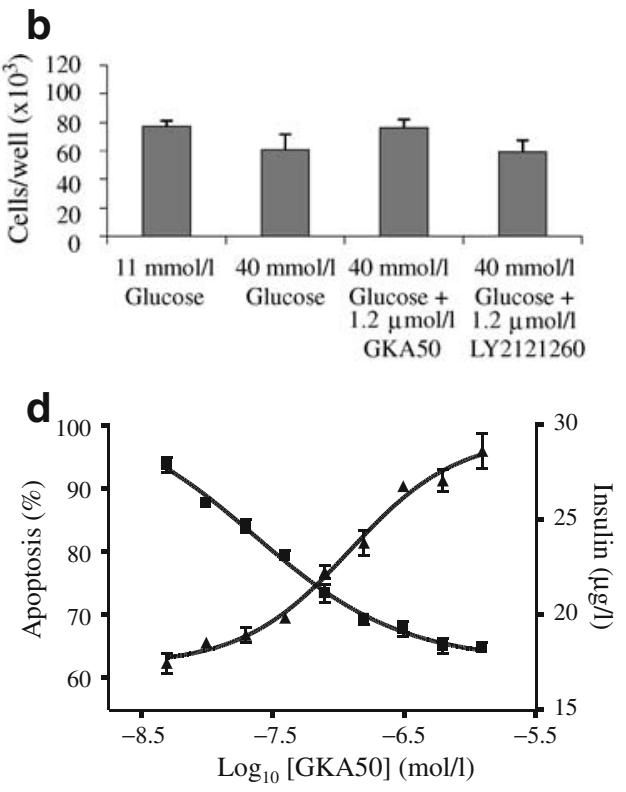

conditions (40 mmol/1 glucose + GKA50 as indicated) for 3 days. Caspase-3 activity was measured in one set of the cells. For the other set of cells, the medium containing high glucose and compounds was removed and replaced with medium containing $2.5 \mathrm{mmol} / \mathrm{l}$ glucose. After $2 \mathrm{~h}$ recovery, the cells were subsequently stimulated with KRB supplemented with $16 \mathrm{mmol} / \mathrm{l}$ glucose. Cell medium was collected and insulin content was measured using an ELISA. Square, apoptosis; triangle, insulin

chronic high glucose. The competition experiments were conducted as follows. We examined whether a fixed amount of competitor compound $(1.2 \mu \mathrm{mol} / \mathrm{l})$ was able to reduce the potency of GKA50 in preventing cell apoptosis. We found that both competitors were able to compete with GKA50 and cause a loss in potency of GKA50 in its antiapoptotic activity. The reduction in the potency of GKA50 by the competitors correlated well with their biochemical

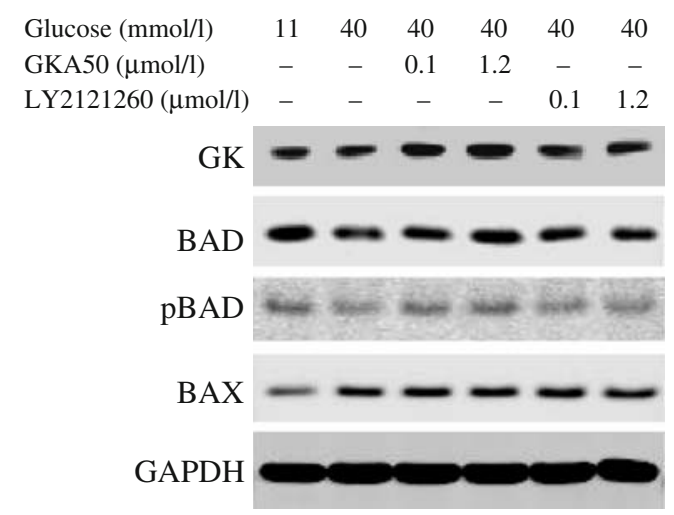

Fig. 5 GKA50 inhibits beta cell apoptosis through regulation of GK and apoptotic proteins. INS- 1 cells were treated with $40 \mathrm{mmol} / 1$ glucose and compound for 3 days. Cell lysates were subjected to immunoblot analysis for $\mathrm{GK}$, total $\mathrm{BAD} / \mathrm{pBAD}$ and $\mathrm{BAX}$ 
$\mathrm{EC}_{50}$ values (competition by Compound A > LY2121260) (Figs 1 and 6). We have also conducted a competition experiment in which we kept GKA50 at the concentration at which $90-100 \%$ inhibition of apoptosis was achieved, and instead increased the amount of the competitor compound. Consistently, we observed that the competitor decreased the ability of GKA50 to inhibit apoptosis. The rank order of competition correlated with the corresponding biochemical potency of the competitor compound (data not shown). These results suggest that direct binding to the GK protein is essential for GKA50 to reduce the apoptosis induced by chronic high glucose.

\section{Discussion}

GK is the rate-limiting enzyme that converts glucose into glucose 6-phosphate and serves as the glucose sensor for glucose-stimulated insulin secretion in beta cells. By activating GK activity, GKAs stimulate insulin secretion in islets and glucose metabolism in hepatocytes, lowering blood glucose in a range of non-diabetic and diabetic rodent models. Therefore, they provide an opportunity for the therapeutic treatment of type 2 diabetes [18-20]. Our study suggests a novel role of GKAs as potential regulators of islet cell mass through promotion of beta cell proliferation and prevention of beta cell death induced by chronic high glucose.

Using a heterozygous $G k$ knockout mouse $\left(G k^{\mathrm{del} / \mathrm{wt}}\right)$, Gorman et al. reported that $G k^{\mathrm{del} / \mathrm{wt}}$ mice, when on a high-fat diet, had reduced insulin levels and greater hyperglycaemia compared with $G k^{\mathrm{wt} / \mathrm{wt}}$ controls [21]. Their results were consistent with decreased GK in beta cell specific $G k^{+/-}$mice leading to insufficient beta cell hyperplasia in response to high-fat-induced insulin resistance [7].

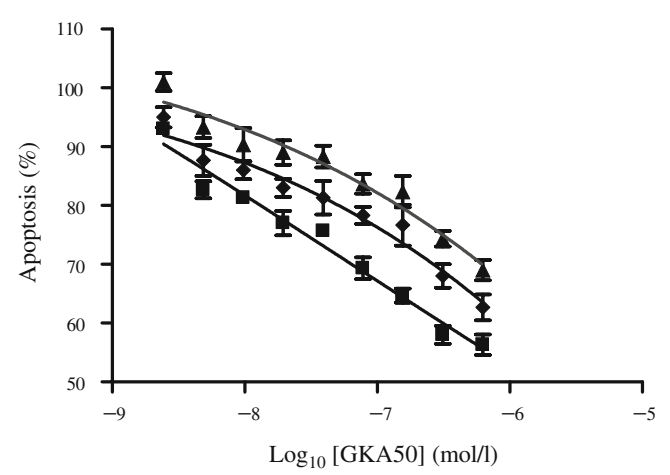

Fig. 6 The anti-apoptotic effect of GKA50 is abrogated by other GKAs lacking anti-apoptotic activity. INS-1 cells were cultured with medium containing $40 \mathrm{mmol} / \mathrm{l}$ glucose and various concentrations of GKA50 with or without $1.2 \mu \mathrm{mol} / 1$ of competitor compound for 3 days. Caspase- 3 activity was measured. The results shown represent the mean \pm SEM from triplicate assays. Square, no competitor; diamond, LY2121260; triangle, Compound A
These findings were the first to suggest a critical requirement for GK, not only for insulin secretion but also for beta cell replication. Our results further demonstrate that enhancing GK activity by GKAs promotes beta cell proliferation (Fig. 2) and support the suggestion that glucose metabolism is crucial for beta cell growth [22, 23]. Hypothetically, GKAs should be able to increase GK activity in beta cell specific $G k^{+-}$mice and hence render them with sufficient beta cell compensation for high-fat-induced insulin resistance and protect them against diabetes.

Both IRS-2 and PKB/AKT have previously been shown to play important roles in pancreatic beta cell growth and survival. Irs $2^{-/-}$mice develop diabetes because of a lack of beta cell hyperplasia in response to insulin resistance [24, 25]. Activation of the PKB/AKT pathway is required for glucose-induced beta cell proliferation and survival because of constitutively active PKB/AKT-enhanced survival in the cells [26]. Recently, Lingohr et al. reported that glucose specifically upregulates IRS-2 in rat primary pancreatic islet beta cells and IRS-2 upregulation correlates with downstream activation of PKB [17]. We have observed a similar increase in phosphorylation of PKB/AKT after GKA treatment together with IRS-2 induction. Therefore, the action of GKAs is consistent with that of glucose, suggesting that GKAs promote beta cell proliferation via the IRS-2/phosphoinositide 3-kinase/PKB branch of the IRS-2 signalling pathways. Because promotion of beta cell proliferation by GKAs may depend, at least in part, upon IRS-2 signalling pathways, it would be quite instructive to determine whether GKAs promote beta cell proliferation in $\operatorname{Irs} 2^{-1-}$ mice.

Results from Lingohr et al. suggest that specific induction of IRS-2 production by glucose occurs at the transcription level. It depends on glucose metabolism and requires a downstream increase in cytosolic $\left[\mathrm{Ca}^{2+}\right]_{\mathrm{i}}[17]$. Johnson et al. recently demonstrated that GKA50 is able to raise $\left[\mathrm{Ca}^{2+}\right]_{\mathrm{i}}$ in the presence of $2-10 \mathrm{mmol} / \mathrm{l}$ glucose in beta cells [27]. Collectively, these findings suggest that GKAs may regulate IRS-2 production through enhancement of glucose metabolism and subsequent elevation of cytosolic $\left[\mathrm{Ca}^{2+}\right]_{\mathrm{i}}$ in beta cells.

Interestingly, IRS-2-mediated activation of PKB/AKT pathway by glucagon-like peptide-1 (GLP-1) and its analogue, exendin- 4 , has also been demonstrated to play a role in the regulation of beta cell proliferation $[12,28]$. Although GLP-1 and GKAs stimulate insulin secretion and lower blood glucose via distinct actions, they may use this common pathway to regulate beta cell mass in the pancreas. It is likely that, as with GLP-1, GKAs regulate IRS-2 production in beta cells, which in turn could be a major contributory mechanism underlying the promotion of beta cell growth and survival. Thus, specific induction of IRS-2 by GKAs or GLP-1 provides a potential means of 
promoting beta cell survival, maintaining adequate beta cell mass and delaying the onset of diabetes.

Whether glucose signalling plays a dominant role in beta cell compensation for insulin resistance has been debated [29]. The finding that a reduction in GK levels in beta cells prevents beta cell expansion [7] and our results showing that enhancing GK activity by GKAs leads to an increase in INS-1 cell proliferation support the hypothesis that glucose and GK activity are crucial factors responsible for this important compensatory mechanism. Future investigations will be necessary to understand how glucose signalling is involved in beta cell replication.

Although recent studies suggest that chronic hyperglycaemia can induce apoptosis of beta cells ultimately leading to a decrease in beta cell mass [30-32], the mechanisms causing these phenomena are not well understood. It has been suggested that glucose metabolism may be essential for apoptosis [33]. All the GKAs tested in this study were expected to enhance glucose metabolism by increasing GK activity, but only one compound (GKA50) displayed significant anti-apoptotic activity. This observation argues that enhancement of glucose metabolism may be important but is not sufficient to prevent apoptosis.

Direct involvement of GK in cell apoptosis was not revealed until Danial et al. reported that in liver cells GK is associated with the pro-apoptotic protein $\mathrm{BAD}$, a member of the BCL-2 family [9]. Direct interaction between GK and $\mathrm{pBAD}$ reduced binding of BAX to mitochondria and enhanced glucose metabolism, which led to inhibition of BAX-induced apoptosis [9]. In MIN6N8 beta cells, chronic high glucose causes a significant reduction in GK protein and pBAD in apoptotic cells [10]. Both events are believed to be associated with apoptosis induced by chronic exposure to high glucose.

We observed that the anti-apoptotic compound GKA50 caused a specific increase in GK protein and normalisation of $\mathrm{BAD} / \mathrm{pBAD}$ in INS-1 cells, while GK production was not affected by chronic high glucose treatment (Fig. 5). The effect of GKA50 treatment is consistent with a previous observation that GK overproduction prevents apoptosis induced by chronic high glucose by enhancing the interaction of GK and mitochondria, increasing $\mathrm{BAD}$ phosphorylation and reversing other events that lead to apoptosis [10]. Although GKA50 treatment did not reduce BAX protein in the INS-1 cells as GK overproduction did in MIN6N8 cells, it is conceivable that the increased levels of GK that occurred because of GKA50 in the cells may be sufficient to block the binding of BAX to mitochondria, one of the key events leading to cell apoptosis.

It remains unclear at this point why only GKA50, and not any other GKA tested, was able to reduce apoptosis induced by chronic high glucose in the INS-1 cells. While treatment with GKA50 increased the level of pBAD, and
LY2121260 did not, the magnitude was quite modest at any time point tested (Fig. 5 and data not shown). The exact mechanism for the prevention of cell apoptosis by this compound warrants further investigation. Based on our observation and reports by others, we speculate that it is the induction of GK protein and subsequent modulation of $\mathrm{BAD} / \mathrm{pBAD}$ by this agent that contributes to its antiapoptotic effect in this cell line. More compounds of differing activities will be needed to address this question. It is always dangerous to extrapolate from a tumour cell line, but given that tumour cell lines are generally more resistant to induced apoptosis than primary cells, we consider that these findings merit further study. Investigation of the effects of various GKAs in animal models of diabetes will be necessary to better understand the relevance of the anti-apoptotic effects of GKAs shown in the present study and the differences in the GKA compounds.

In conclusion, we have shown for the first time that GKAs play important roles in the promotion of proliferation in a model INS-1 beta cell line and prevention of apoptosis induced by chronic exposure to high glucose levels. The effect of GKAs on specific regulation of IRS-2 suggests possible long-term effects on beta cell mass. These novel GKAs may offer potential therapeutics that not only decrease hyperglycaemia but also compensate for beta cell loss in patients with type 2 diabetes.

Acknowledgements The authors thank J. Lou, F. Guo, T. O. Johnson (Pfizer) for synthesising the compounds, and A. N. Fanjul (Pfizer) for critical reading and helpful comments.

Duality of interest The authors declare that there is no duality of interest associated with this manuscript.

\section{References}

1. Butler AE, Janson J, Soeller WC, Butler PC (2003) Increased beta-cell apoptosis prevents adaptive increase in beta-cell mass in mouse model of type 2 diabetes: evidence for role of islet amyloid formation rather than direct action of amyloid. Diabetes 52:23042314

2. Rhodes CJ (2005) Type 2 diabetes - a matter of beta-cell life and death? Science 307:380-384

3. Matschinsky FM, Ellerman JE (1968) Metabolism of glucose in the islets of Langerhans. J Biol Chem 243:2730-2736

4. Matschinsky FM (2002) Regulation of pancreatic beta-cell glucokinase: from basics to therapeutics. Diabetes 51(Suppl 3): S394-404

5. Tsakiris D, Ioannou K (2004) An underdiagnosed type of diabetes: the MODY syndromes. Pathophysiology, clinical presentation and renal disease progression. J Nephrol 17:637-641

6. Grimsby J, Sarabu R, Corbett WL et al (2003) Allosteric activators of glucokinase: potential role in diabetes therapy. Science 301:370-373

7. Terauchi Y, Takamoto I, Kubota N et al (2007) Glucokinase and IRS-2 are required for compensatory beta cell hyperplasia in 
response to high-fat diet-induced insulin resistance. J Clin Invest 117:246-257

8. Downward J (2003) Cell biology: metabolism meets death. Nature 424:896-897

9. Danial NN, Gramm CF, Scorrano L et al (2003) BAD and glucokinase reside in a mitochondrial complex that integrates glycolysis and apoptosis. Nature 424:952-956

10. Kim WH, Lee JW, Suh YH et al (2005) Exposure to chronic high glucose induces beta-cell apoptosis through decreased interaction of glucokinase with mitochondria: downregulation of glucokinase in pancreatic beta-cells. Diabetes 54:2602-2611

11. Heredia VV, Thomson J, Nettleton D, Sun S (2006) Glucoseinduced conformational changes in glucokinase mediate allosteric regulation: transient kinetic analysis. Biochemistry 45:7553-7562

12. Wang Q, Li L, Xu E, Wong V, Rhodes C, Brubaker PL (2004) Glucagon-like peptide-1 regulates proliferation and apoptosis via activation of protein kinase B in pancreatic INS-1 beta cells. Diabetologia 47:478-487

13. Brocklehurst KJ, Payne VA, Davies RA et al (2004) Stimulation of hepatocyte glucose metabolism by novel small molecule glucokinase activators. Diabetes 53:535-541

14. McKerrecher D, Allen JV, Caulkett PW et al (2006) Design of a potent, soluble glucokinase activator with excellent in vivo efficacy. Bioorg Med Chem Lett 16:2705-2709

15. Efanov AM, Barrett DG, Brenner MB et al (2005) A novel glucokinase activator modulates pancreatic islet and hepatocyte function. Endocrinology 146:3696-3701

16. Kamata K, Mitsuya M, Nishimura T, Eiki J, Nagata Y (2004) Structural basis for allosteric regulation of the monomeric allosteric enzyme human glucokinase. Structure 12:429-438

17. Lingohr MK, Briaud I, Dickson LM et al (2006) Specific regulation of IRS-2 expression by glucose in rat primary pancreatic islet beta-cells. J Biol Chem 281:15884-15892

18. Leighton B, Atkinson A, Coghlan MP (2005) Small molecule glucokinase activators as novel anti-diabetic agents. Biochem Soc Trans 33:371-374

19. Sarabu R, Grimsby J (2005) Targeting glucokinase activation for the treatment of type 2 diabetes - a status review. Curr Opin Drug Discov Dev 8:631-637

20. Matschinsky FM, Magnuson MA, Zelent D et al (2006) The network of glucokinase-expressing cells in glucose homeostasis and the potential of glucokinase activators for diabetes therapy. Diabetes 55:1-12
21. Gorman T, Hope DC, Brownlie R et al (2008) Effect of high-fat diet on glucose homeostasis and gene expression in glucokinase knockout mice. Diabetes Obes Metab 10:885-897

22. Cousin SP, Hugl SR, Myers MG Jr, White MF, Reifel-Miller A, Rhodes CJ (1999) Stimulation of pancreatic beta-cell proliferation by growth hormone is glucose-dependent: signal transduction via janus kinase 2 (JAK2)/signal transducer and activator of transcription 5 (STAT5) with no crosstalk to insulin receptor substratemediated mitogenic signalling. Biochem J 344:649-658

23. Ashcroft SJ (1980) Glucoreceptor mechanisms and the control of insulin release and biosynthesis. Diabetologia 18:5-15

24. Withers DJ, Gutierrez JS, Towery H et al (1998) Disruption of IRS-2 causes type 2 diabetes in mice. Nature 391:900-904

25. Kubota N, Tobe K, Terauchi Y et al (2000) Disruption of insulin receptor substrate 2 causes type 2 diabetes because of liver insulin resistance and lack of compensatory beta-cell hyperplasia. Diabetes 49:1880-1889

26. Srinivasan S, Bernal-Mizrachi E, Ohsugi M, Permutt MA (2002) Glucose promotes pancreatic islet beta-cell survival through a PI 3-kinase/Akt-signaling pathway. Am J Physiol 283:E784-793

27. Johnson D, Shepherd RM, Gill D, Gorman T, Smith DM, Dunne MJ (2007) Glucose-dependent modulation of insulin secretion and intracellular calcium ions by GKA50 - a glucokinase activator. Diabetes 56:1694-1702

28. Park S, Dong X, Fisher TL et al (2006) Exendin-4 uses Irs2 signaling to mediate pancreatic beta cell growth and function. J Biol Chem 281:1159-1168

29. Weir GC, Bonner-Weir S (2007) A dominant role for glucose in beta cell compensation of insulin resistance. J Clin Invest 117:81-83

30. Kaiser N, Leibowitz G, Nesher R (2003) Glucotoxicity and betacell failure in type 2 diabetes mellitus. J Pediatr Endocrinol Metab 16:5-22

31. Pick A, Clark J, Kubstrup C et al (1998) Role of apoptosis in failure of beta-cell mass compensation for insulin resistance and beta-cell defects in the male Zucker diabetic fatty rat. Diabetes 47:358-364

32. Donath MY, Gross DJ, Cerasi E, Kaiser N (1999) Hyperglycaemiainduced beta-cell apoptosis in pancreatic islets of Psammomys obesus during development of diabetes. Diabetes 48:738-744

33. Gottlob K, Majewski N, Kennedy S, Kandel E, Robey RB, Hay N (2001) Inhibition of early apoptotic events by Akt/PKB is dependent on the first committed step of glycolysis and mitochondrial hexokinase. Genes Dev 15:1406-1418 